Research Article

\title{
Regulating a Firm under Adverse Selection and Moral Hazard in Uncertain Environment
}

\author{
Jing Feng, Yanfei Lan, and Ruiqing Zhao \\ Institute of Systems Engineering, Tianjin University, Tianjin 300072, China \\ Correspondence should be addressed to Yanfei Lan; yanfei-lan@163.com
}

Received 27 November 2013; Accepted 23 January 2014; Published 5 March 2014

Academic Editor: Dumitru Baleanu

Copyright (C) 2014 Jing Feng et al. This is an open access article distributed under the Creative Commons Attribution License, which permits unrestricted use, distribution, and reproduction in any medium, provided the original work is properly cited.

This paper investigates a problem of how to regulate a firm which has private information about the market capacity, leading to adverse selection, and which can increase the market demand by exerting costly effort, resulting in moral hazard. In such a setting, the regulator offers a regulatory policy to the firm with the objective of maximizing a weighted sum of the consumer surplus and the firm's profit (i.e., the social total surplus). We firstly find that the regulator will set the firm's effort level as zero under observable effort regardless of the market capacity being full or private information; that is, the effort has no impact on the optimal regulatory policy. Interestingly, we also show that, it is necessary for regulator to consider the difference between the effort's impact on the demand and the price's impact on the demand, which may generate different distortion effects about the regulatory policy.

\section{Introduction}

In order to keep a regulated firm from abusing its monopoly power, the price regulation problem arises. If the regulator knows the products' information, such as cost and demand, the optimal regulatory policy is that the firm should follow marginal cost pricing and be subsidized for the fixed cost. However, the regulator often does not know the products' information, which takes the form of the firm's hidden characteristic or type about the products and the firm's hidden action or effort leading to the so-called adverse selection and moral hazard problems, respectively (see $[1,2])$. Previous literature typically studies the regulatory problems in isolation (i.e., either a moral hazard or an adverse selection setting is examined), but, in reality, moral hazard and adverse selection often emerge in regulatory problems simultaneously. Therefore, the studying of how the linkage between moral hazard and adverse selection affects the optimal regulatory policy will become more and more important.

We study a regulatory problem under moral hazard and adverse selection in which the regulator regulates a firm to produce a kind of products and then sells them to the consumer with exerting some effort. The market demand for the products depends on three factors: the market capacity, the products' unit price, and the firm's effort level, in which the firm possesses private information about the market capacity. Despite the regulator does not know the true market capacity, he has a subjective assessment about it. Meanwhile, the regulator often cannot observe the firm's effort level exerted on the demand. The regulator is a regulatory policy designer, who offers a regulatory policy menu that consists of a unit price of products and a transfer payment. Therefore, under this setting, the problem facing the regulator is how does he design the optimal regulatory policy with the objective of maximizing the social total surplus, that is, a weighted sum of the consumer surplus and the firm's profit. And then we first analyze such problems that the firm's effort is observable and unobservable when the market capacity is known to the regulator, respectively. Furthermore, we extend the analysis to the scenario that the market capacity is private information. In this paper, we will focus on two important questions.

(1) First, how the private information and the firm's effort affect the optimal regulatory policy, respectively?

(2) Second, how the combining between adverse selection and moral hazard affects the optimal regulatory policy?

Several important insights are derived from our model. Firstly, we show that the regulator will set the firms' effort level 
as zero under observable effort whether the market capacity is full or private information; that is, the effort has no impact on the optimal regulatory policy regardless of the market capacity being full or private information. It is worth noting that private information does not give rise to any distortion so long as the effort level can be observable to the regulator. Secondly, we also highlight that it is necessary for regulator to consider the difference between the effort's impact on the demand and the price's impact on the demand, which may generate different distortion effects about the regulatory policy regardless of the market capacity being full or private information. In other words, based on the difference, the regulator will design different regulatory policies.

In the following, we will introduce the prior literature in the domain about adverse selection and moral hazard. On the one hand, there is a large body of literature on regulatory policy design with adverse selection, for example, Baron and Myerson [3], Lewis and Sappington [4], Baron and Besanko [5], Sappington [6], Sappington and Sibley [7], Laffont and Rochet [8], Laffont and Tirole [9], Aguirre and Beitia [10], and Lan et al. [11]. Baron and Myerson [3] studied the firm that has private information of its cost, while Lewis and Sappington [4] considered that the firm possesses private information about the demand. Furthermore, Lewis and Sappington [12] expanded on Lewis and Sappington [4] by adding a second dimension of adverse selection. Both the firm's cost and the market demand are the firm's private information. Aguirre and Beitia [10] modified the model of Lewis and Sappington [4] by considering costly public funds. These papers are related to ours, as we have done, and each of these papers uses an adverse selection model to determine the regulator's optimal regulatory policy. However, none of these papers considers a dimension of moral hazard, the firm's effort, or otherwise. Our paper is different from theirs. We introduce the impact of the firm's effort on the demand to the model, which makes the studying of regulatory problem more significant. This difference is important, which leads to different conclusions under the setting with moral hazard from that under the setting without moral hazard.

On the other hand, there is a substantial literature that describes the roles of moral hazard in regulatory problems (see [1,2] for useful reviews). Cowan [13] analyzed an optimal risk-sharing problem between consumers and the regulated firm in a full information framework. Laffont and Tirole [9] and Lewis and Sappington [14] discussed how regulated prices are optimally altered when they must serve both to motivate the delivery of high-quality products and to limit incentives to misrepresent private information. Lewis and Sappington [15] noted that consumers and the regulated firm can both suffer when the level of realized service quality is not verifiable. In contrast, Dalen [16] showed that in a dynamic setting where the regulator's commitment powers are limited, consumers may benefit when quality is not verifiable. However, these papers have not been explored in the case of adverse selection, and our paper covers the gap.

To the best of our knowledge, studying the mixed model combining adverse selection and moral hazard in regulatory policy is so scarce. Laffont and Tirole [17] introduced possibly noisy cost observability as well as an unobservable effort variable, and the regulator can observe the firm's output and cost but not its efficiency parameter, its effort, and the cost disturbance, and the payment to the firm is based on a firm's effort observed ex post by the regulator. Perrigne and Vuong [18] extended the model of Laffont and Tirole [17] and considered a firm producing the products subject to general random demand and cost functions. Our paper is related to Laffont and Tirole [17]. They focused on the studying of how to regulate a firm when the firm's cost is its private information and the effort level for reducing cost is unobservable to the regulator. Our paper is different from theirs, we assume that the regulator does not know the market capacity and also cannot observe the firm's effort exerted on the demand, and under such setting, how the regulator designs the optimal regulatory policy.

In addition, previous research typically assumes that the demand is always considered to be deterministic or stochastic in regulatory problems. However, due to the lack of historical data, considering the uncertainty as randomness is not reasonable in this situation. For the reason, a new approach, based on the experts' judgement, called uncertainty theory, was proposed by Liu [19] and refined by Liu [20]. From then on, uncertainty theory has gradually become a powerful mathematical tool to deal with various problems under private information, for example, uncertain control [20,21], uncertain differential equation [22], uncertain principal agent [23-28], and uncertain programming and applications [23, 24, 28-30]. Motivated by this, this paper studies a regulation problem, in which the market capacity which is characterized as an uncertain variable with known distribution is the firm's private information.

The remainder of the paper is organized as follows. Section 2 recalls some fundamental concepts and formulas about uncertain variable. Section 3 gives the problem formulation. Section 4 develops two models that analyze the optimal regulatory policy with observable effort and without it in the case of full information, respectively, and discusses the unobservable effort's impact on the regulatory policy. Section 5 further investigates the optimal regulatory policy with observable effort and without that in the case of private information and also discusses how private information and unobservable effort affect the optimal regulatory policy simultaneously. We provide concluding remarks and some avenues for future research in Section 6. The proofs of all the formal results are relegated to an appendix.

\section{Preliminary}

As a branch of axiomatic mathematics, uncertainty theory was founded by Liu [19] and subsequently studied by many researchers. Assume that $\Theta$ is a nonempty set and $\mathscr{L}$ is a $\sigma$ algebra of $\Theta$. Each element $\Lambda$ in $\mathscr{L}$ is called an event. A set function $\mathscr{M}$ from $\mathscr{L}$ to $[0,1]$ is called an uncertain measure if it satisfies the following axioms.

Axiom 1 (Normality). $\mathscr{M}\{\Theta\}=1$ for the universal set $\Theta$.

Axiom 2 (Duality). $\mathscr{M}\{\Lambda\}+\mathscr{M}\left\{\Lambda^{c}\right\}=1$, for all $\Lambda \in \mathscr{L}$. 
Axiom 3 (Subadditivity). $\mathscr{M}\left\{\bigcup_{i=1}^{\infty} \Lambda_{i}\right\} \leq \sum_{i=1}^{\infty} \mathscr{M}\left\{\Lambda_{i}\right\}$, for all $\Lambda_{i} \in \mathscr{L}, i=1,2, \ldots$

Axiom 4 (Product). Let $\left(\Theta_{k}, \mathscr{L}_{k}, \mathscr{M}_{k}\right)$ be uncertainty spaces for $k=1,2, \ldots$ Then the product uncertain measure $\mathscr{M}$ is an uncertain measure satisfying

$$
\mathscr{M}\left\{\prod_{k=1}^{\infty} \Lambda_{k}\right\}=\bigwedge_{k=1}^{\infty} \mathscr{M}_{k}\left\{\Lambda_{k}\right\}
$$

where $\Lambda_{k}$ are arbitrarily chosen events from $\mathscr{L}_{k}$ for $k=$ $1,2, \ldots$, respectively.

Definition 1 (see [19]). An uncertain variable is a measurable function $\xi$ from an uncertainty space $(\Theta, \mathscr{L}, \mathscr{M})$ to the set of real numbers; that is, for any Borel set $B$ of real numbers, the set $\{\xi \in B\}=\{\theta \in \Theta \mid \xi(\theta) \in B\}$ is an event.

Definition 2 (see [19]). The uncertainty distribution $\Phi$ of an uncertain variable $\xi$ is defined by $\Phi(x)=\mathscr{M}\{\xi \leq x\}$ for any real number $x$.

Definition 3 (see [19]). Let $\xi$ be an uncertain variable defined on the uncertainty space $(\Theta, \mathscr{L}, \mathscr{M})$. Then the expected value of $\xi$ is defined by

$$
\mathbf{E}[\xi]=\int_{0}^{+\infty} \mathscr{M}\{\xi \geq r\} \mathrm{d} r-\int_{-\infty}^{0} \mathscr{M}\{\xi \leq r\} \mathrm{d} r
$$

provided that at least one of the two integrals is finite.

Lemma 4. If: $\mathfrak{R} \rightarrow \mathfrak{R}$ is an increasing function and $\xi$ is an uncertain variable with continuous membership function and finite expected value, then

$$
\mathbf{E}[f(\xi)]=\int_{-\infty}^{+\infty} f(x) \phi(x) d x
$$

provided that the integral is finite.

\section{The Model}

Consider a regulation problem involves three participants: the regulator (he), a firm (she), and the consumer. The firm produces a kind of products and then sells them to the consumer with exerting some effort, and then the consumer gives a payment for the products at a given unit price, $p$, and meanwhile pays a transfer payment $t$. The market demand for the products, which equals the firm's output, depends on three factors: the market capacity $Y$, the products' price $p$, and the firm's effort level $e$. The regulator does not know the market capacity $Y$ which is the firm's private information. And the firm's effort level is not observable to the regulator. Therefore, the problem facing the regulator is thus a mixture of moral hazard (postcontractual opportunism associated with the effort decision) and adverse selection (precontractual asymmetric information regarding the market capacity). This allows us to study different information regimes in which the market capacity and/or effort level may be hidden to the regulator. To maximize the social total surplus, the regulator
TABLE 1: The four information cases.

\begin{tabular}{lcc}
\hline & $Y$ known & $Y$ unknown \\
\hline Without moral hazard & Case OF & Case OP \\
With moral hazard & Case UF & Case UP \\
\hline
\end{tabular}

specifies the unit price for the products and the transfer payment, which may be thought of as apportioned among consumers in such a manner that no consumer is excluded from purchasing the products.

The market demand adopts the following additive form:

$$
q=Y-b p+v e .
$$

The coefficients $b$ and $v$ measure, respectively, a demand sensitivity in response to the price change and the effectiveness of the firm's effort in enhancing the demand of the product. Expending effort level's cost $\psi(e)=e^{2} / 2$, which is an increasing and convex function. Other function forms for the cost of effort can be used without fundamentally changing the analysis. Moreover, presume that $Y$ is sufficient large so that the demand is nonnegative.

Thus, the firm's profit can be deduced as

$$
\pi(p, t, e, Y)=(p-c)(Y-b p+v e)-D-\psi(e)+t,
$$

where $c$ is the firm's marginal cost and $D$ is the fixed cost. To avoid trivial cases, assume $p \geq c$. The consumer surplus

$$
S(p, t, e, Y)=V(Y-b p+v e)-p(Y-b p+v e)-t,
$$

where $V(\cdot)$ is the consumer's utility function, and assume that the consumer is risk averse with $V^{\prime}(\cdot)>0, V^{\prime \prime}(\cdot) \leq 0$ (see [17]).

The regulator's objective is to maximize a weighted sum of the consumer surplus and the firm's profit (see [3]), that is, the social total surplus

$$
W(p, t, e, Y)=S(p, t, e)+\alpha \Pi(p, t, e),
$$

where $0 \leq \alpha \leq 1$, which implies that the regulator pays more attention to the consumer surplus than the firm's profit.

The regulator designs a regulatory policy, while the firm decides whether or not to accept the regulatory policy and, if so, how much effort level to exert. More specially, the sequence of events is as follows. (1) The regulator offers a regulatory policy. (2) The firm privately observes the value of market capacity. (3) The firm decides whether or not to participate and if so, which regulatory policy to sign and makes the effort level decision. (4) The firm produces the products and then sells them to the consumer. (5) The consumer gives the payments to the firm for the products; meanwhile, the market demand is realized.

Our main focus in this paper is to investigate how the information structure and the firm's effort level affect the optimal regulatory policy. In doing so, we will analyze four cases which are shown in Table 1 . The first two cases, OF and UF, represent the scenario in which the regulator knows the market capacity. The remaining two cases OP and UP represent the scenario for which the regulator does not know the market capacity. 


\section{Full Information}

We firstly solve the problem under full information; that is, the market capacity is known to the regulator, which is characterized by $Y=y$. Then we will obtain the firstbest situations, to serve as a benchmark to the case with private information. And in the following, we will focus on two different problems: one assumes that the regulator is omniscient (able to observe both the market capacity and the firm's effort), while the other assumes that the regulator cannot observe the firm's effort.

4.1. Observable Effort (Case OF). To determine the impact of the firm's effort on the optimal regulatory policy, we begin with focusing on the case that the firm's effort is observable to the regulator, and the regulator also knows the true market capacity $y$. Under this case, the regulator can specify the effort level to be exerted by the firm as well as price and transfer payment; that is, the regulator offers a regulatory policy $(p, t, e)$ with the objective of maximizing the social total surplus. When the regulator designs the regulatory policy, he must take into account the firm's participation constraint; that is to say, he must ensure the firm to obtain at least as great as her reservation profit; in this paper, we simplified her reservation profit as zero. Therefore, to maximize the social total surplus, the regulator's problem can be formulated as follows:

$$
\begin{array}{ll}
\max _{(p, t, e)} & W(p, t, e, y) \\
\text { subject to : } & (p-c)(y-b p+v e) \\
& -D-\psi(e)+t \geq 0 .
\end{array}
$$

Theorem 5. Under Case OF, the optimal regulatory policy $\left(p^{\mathrm{OF}}, t^{\mathrm{OF}}, e^{\mathrm{OF}}\right)$ details

$$
\begin{gathered}
V^{\prime}\left(y-b p^{O F}\right)=c, \\
e^{O F}=0, \\
t^{O F}=D-\left(p^{O F}-c\right)\left(y-b p^{O F}\right) .
\end{gathered}
$$

Equation (10) implies that the optimal regulatory policy under Case OF is consistent with that under without effort; in other words, when the regulator can observe the firm's effort, he will leave the effort level with zero. The reason is intuitively. When the regulator is omniscient, with more flexibility, it is not surprising that he can always regulate the market demand via adjusting the products' price rather than setting an effort level, as the effort needs to expend extra cost, which is paid by the consumer. This will lead to the consumer surplus reduced. Therefore, under Case OF, the observable effort exerted by the firm has no impact on the optimal regulatory policy.

In addition, under Case OF, we find that the first-best regulatory policy makes the firm get zero profit; specifically, the optimal price satisfies that the marginal utility of the consumer is equal to the marginal cost of the firm, and the optimal transfer payment compensates the firm's cost, ensuring that the firm obtains her reservation profit, that is, zero profit. Consequently, the consumer captures all surplus. The reason why the regulator leaves the firm with zero profit is that the regulator pays more attention to the consumer surplus.

4.2. Unobservable Effort (Case UF). Now we turn to consider the case that the firm's effort is not observable to the regulator, and then the regulator's optimization problem changes slightly. In particular, the effort level $e$ becomes the firm's decision variable rather than that of the regulator. The firm's choice of effort level depends on the regulatory policy designed by the regulator. Furthermore, the firm will choose her effort level to maximize her own profit. As for the regulator, he will offer the regulatory police $(p, t)$; meanwhile, he can anticipate the firm's optimal reaction to the regulatory policy, $e^{*}$, and incorporates it as a constraint in his maximization problem as seen below:

$$
\begin{array}{ll}
\max _{\left(p, t, e^{*}\right)} & W\left(p, t, e^{*}, y\right) \\
\text { subject to : } & (p-c)\left(y-b p+v e^{*}\right) \\
-D-\psi\left(e^{*}\right)+t \geq 0 \\
e^{*} \in \arg \max _{e}(p-c)(y-b p+v e) \\
-D-\psi(e)+t .
\end{array}
$$

The first constraint is the firm's participation constraint, which guarantees that the firm earns at least her reservation profit, normalized to zero in our analysis. The second constraint is the incentive constraint, reflecting the firm's optimization problem in choosing the optimal effort level.

Theorem 6. Under Case UF, the optimal regulatory policy $\left(p^{U F}, t^{U F}, e^{U F}\right)$ details

$$
\begin{gathered}
V^{\prime}\left(y-\left(b-v^{2}\right) p^{U F}-c v^{2}\right)=c-\frac{v^{2}}{b-v^{2}}\left(p^{U F}-c\right), \\
e^{U F}=v\left(p^{U F}-c\right), \\
t^{U F}=D+\frac{v^{2}\left(p^{U F}-c\right)^{2}}{2} \\
-\left(p^{U F}-c\right)\left[y-\left(b-v^{2}\right) p^{U F}-c v^{2}\right] .
\end{gathered}
$$

We can explain Theorem 6 from the following two aspects. On the one hand, when $b<v^{2}$, representing that the effort's impact on demand is stronger than the price's impact on demand, the demand is increasing in the price. Such a conclusion alters the price's impact on the demand when there is no effort. Moreover, note that (13) demonstrates that the consumer's marginal utility is distorted upwards from that under case OF. The increasing value of the consumer's marginal utility depends on the firm's marginal profit $p^{\mathrm{UF}}-c$, and the consumer's marginal utility is increasing in $p^{\mathrm{UF}}-$ $c$. This means that the firm's marginal profit's increase will lead to the increase of the consumer's marginal utility. As 
for the firm's profit, by substituting $t^{\mathrm{UF}}$ into the firm's profit function, we can obtain that the firm's profit is zero, which demonstrates that the firm's effort does not benefit herself but, instead, increases the consumer's marginal utility. The reason is that the regulator can control the firm's profit under full information, even though the effort level is not observable. On the other hand, when $b>v^{2}$, the result is reverse. That is, when the effort's impact on demand is weaker than the price's impact on demand, the firms' effort level brings about the consumer's marginal utility reduced. The decrease of consumer's marginal utility depends on the increase of firm's marginal profit, that is, $p^{\mathrm{UF}}-c$.

It is important to notice that the optimal effort level $e^{\mathrm{UF}}$ satisfies that the marginal cost of effort is equal to the firm's marginal profit and is increasing in $p^{\mathrm{UF}}$. In other words, the higher the price is, the higher the effort level is. The reason is that the regulator may raise the price to limit the demand, whereas it is inevitable for the firm to improve the effort level to increase the demand to pursue more profit.

\subsection{The Effects of Effort}

Proposition 7. Let $p^{O F}$ and $p^{U F}$ be the optimal prices under Cases $O F$ and $U F$, respectively. When $b<v^{2}$,

$$
p^{O F}<p^{U F} \text {. }
$$

The inequality (16) indicates that the optimal price $p^{\mathrm{UF}}$ is distorted upwards from $p^{\mathrm{OF}}$. That is to say, when the firm's effort level gives rise to stronger effect of the demand and is not observable, because the market capacity space may be expanded, the regulator will raise the price to limit the effort's effect on the demand. How is the demand affected when the effort's effect and the price's effect coexist? To understand this, comparing (9) with (13) yields $V^{\prime}\left(y-\left(b-v^{2}\right) p^{\mathrm{UF}}-\right.$ $\left.c v^{2}\right)>V^{\prime}\left(y-b p^{\mathrm{OF}}\right)$, since $V^{\prime \prime}(\cdot) \leq 0$, and we can obtain $y-\left(b-v^{2}\right) p^{\mathrm{UF}}-c v^{2} \leq y-b p^{\mathrm{OF}}$; that is to say, the demand under Case UF is no greater than that under Case OF; that is, $q^{\mathrm{UF}} \leq q^{\mathrm{OF}}$. This means that although the firm prefers to increase demand by exerting effort; however, considering the tradeoff between consumer utility and payments paid to the firm, the regulator still makes the demand reduced through improving the price. And when $b>v^{2}$, it is a pity, and there is no obvious relationship between $p^{\mathrm{UF}}$ and $p^{\mathrm{OF}}$, but we can deduce the relationship between $q^{\mathrm{UF}}$ and $q^{\mathrm{OF}}$. In particular, it follows from $V^{\prime}\left(y-\left(b-v^{2}\right) p^{\mathrm{UF}}-c v^{2}\right)<$ $V^{\prime}\left(y-b p^{\mathrm{OF}}\right)$ that $q^{\mathrm{UF}} \geq q^{\mathrm{OF}}$. Consequently, the difference between the effort's impact on the demand and the price's impact on the demand generates remarkable effect for the distortion of the consumer's marginal utility and the demand. Such the difference inevitably leads to different regulatory policies offered by the regulator taking account to the tradeoff between the consumer utility and payments paid to the firm.

\section{Private Information}

This section takes up the scenario where the market capacity is the firm's private information; that is to say, only the firm knows the true market capacity. Even though the regulator does not know the true market capacity, he has a subjective assessment about it, and this subjective assessment is characterized as an uncertain variable $Y$ with the uncertainty distribution $F(y)$ on the finite and positive support $[y, \bar{y}]$, and $f(y)$ is the derivative of $F(y)$, where $F(y)$ and $f(\bar{y})$ satisfy $(\mathrm{d} / \mathrm{d} y)(f(y) /(1-F(y))) \geq 0$. In the following, we will investigate the optimal regulatory policy with the firm's effort and without it, respectively, and then compare these regulatory policies with the first-best regulatory policies. Doing so will help us illustrate the impact of information structure and the firm's effort on the optimal regulatory policy.

5.1. Observable Effort (Case OP). We firstly consider the case that the regulator can observe the firm's effort level but does not know the market capacity; in this case, the regulator can determine the optimal effort level and restrict his attention to a menu of regulatory policies $(p(y), t(y), e(y))$ that maximizes his expected social total surplus given his subjective assessment about true market capacity. In general, the firm can choose from a wide range of regulatory policy menu designs. However, the direct revelation principle [31] restricts the category of regulatory policy menus by showing that there exists an optimal regulatory policy that induces a truth telling. This allows formulating the regulator's problem as follows:

$$
\begin{array}{cl}
\max _{(p(\cdot), t(\cdot), e(\cdot))} & E[W(p(Y), t(Y), e(Y), Y)] \\
\text { subject to : } & \pi(p(y), t(y), e(y), y) \geq 0, \quad \forall y \in[\underline{y}, \bar{y}] \\
& \pi(p(y), t(y), e(y), y) \\
\geq \pi(p(\hat{y}), t(\hat{y}), e(y), y), & \\
\forall y, \hat{y} \in[\underline{y}, \bar{y}] .
\end{array}
$$

The first constraint is the firm's participation constraint, which guarantees that the firm earns at least her reservation profit, normalized to zero in our analysis. The second constraint is the incentive constraint, which is necessary to ensure that the regulatory policy menu will achieve truthful revelation of the market capacity through the firm's choice of regulatory policy.

To solve Model (17), we firstly find its equivalent model, which is shown in Proposition 8 as follows.

Proposition 8. Model (17) is equivalent to

$$
\begin{aligned}
& \max _{(p(\cdot), e(\cdot))} \int_{\underline{y}}^{\bar{y}}\{V(y-b p(y)+v e(y)) \\
& -c(y-b p(y)+v e(y))-D-\frac{e(y)^{2}}{2} \\
& \left.-(1-\alpha) \frac{1-F(y)}{f(y)}[p(s)-c] \mathrm{d} s\right\} f(y) \mathrm{d} y \\
& \text { subject to: } \quad \frac{\mathrm{d} p(y)}{\mathrm{d} y}>0, \quad \forall y \in[\underline{y}, \bar{y}] \text {. }
\end{aligned}
$$


Theorem 9. Under Case OP, the optimal regulatory policy $\left(p^{O P}(y), t^{O P}(y), e^{O P}(y)\right)$ satisfies

$$
\begin{gathered}
V^{\prime}\left(y-b p^{O P}(y)\right)=c-(1-\alpha) \frac{1-F(y)}{b f(y)}, \\
e^{O P}(y)=0, \\
t^{O P}(y)=D-\left(p^{O P}(y)-c\right)\left(y-b p^{O P}(y)\right) \\
+\int_{\underline{y}}^{y}\left(p^{O P}(s)-c\right) \mathrm{d} s .
\end{gathered}
$$

Equation (20) states that when the firm's effort level is observable, the regulator designs the optimal effort level $e^{\mathrm{OP}}(y)$ as zero, even though the market capacity is her private information. That is because the regulator can always request the effort level to be set at its optimum. That is to say, the regulator can prefer to manipulate the demand by adjusting the pricing policy rather than to let the firm exert effort, as exerting effort has some effort cost, which is undertook by the consumer. Therefore, similar to Case OF, observable effort level has no impact on the optimal regulatory policy although the market capacity is the firm's private information.

From (21), the term $D-\left(p^{P}(y)-c\right)\left(y-b p^{P}(y)\right)$ identifies the firm's cost subsidy to ensure the firm's participation, while the term $\left.\int_{y}^{y}\left[p^{*}(s)-c\right)\right] \mathrm{d} s$ is the information rents paid to the firm in order to induce the firm to tell the truth. Furthermore, it is easy to see that the information rents are increasing in the market capacity $y$, which implies the firm does not have an incentive to understate the market capacity. In particular, the firm will not obtain information rents when $y=y$.

As (19) reveals, the only distortion of the optimal pricing relative to that under Case $\mathrm{OF}$ arises from information rents, which is characterized by the term $(1-\alpha)((1-F(y)) / b f(y))$. Moreover, the term $1-\alpha$ identifies that the regulator is averse to information rents except $\alpha=1$. Moreover, with the decrease of $f(y) /(1-F(y))$, that is, with the increase of $(1-F(y)) / f(y)$, the regulator has more preference to limit information rents; therefore, the optimal price is lower than that under full information.

In sum, under Case OP, the consumer's marginal utility is no greater than the firm's cost, which specifies that the consumer's marginal utility becomes less than that under Case OF. Intuitively, inducing the firm's truthful telling makes the regulator transfer the information rents to the firm, which brings about the consumer's marginal utility worse off than that under full information.

5.2. Unobservable Effort (Case UP). Now we consider Case UP: the regulator's regulatory policy problem can be formulated similar to the one under Case OP; however, since the firm's effort becomes unobservable, the firm determines the optimal effort level through maximizing her own profit. As for the regulator, like Case UF, he will incorporate the optimal effort level as a constraint in his maximization problem as seen below:

$$
\begin{gathered}
\max _{\left(p(\cdot), t(\cdot), e^{*}(\cdot)\right)} \quad E\left[W\left(p(Y), t(Y), e^{*}(Y), Y\right)\right] \\
\text { subject to : } \quad \pi(p(y), t(y), e(y), y) \geq 0, \\
\forall y \in[\underline{y}, \bar{y}] \\
\pi(p(y), t(y), e(y), y) \\
\geq \pi(p(\hat{y}), t(\hat{y}), e(y), y), \\
\forall y, \hat{y} \in[\underline{y}, \bar{y}] \\
e^{*}(y) \in \arg \max _{\widehat{e}(\cdot)} \pi(p(y), t(y), \hat{e}(y), y) .
\end{gathered}
$$

Proposition 10. Model (22) is equivalent to

$$
\begin{aligned}
& \max _{p(\cdot)} \int_{\underline{y}}^{\bar{y}\{V}\left(y-\left(b-v^{2}\right) p(y)-c v^{2}\right) \\
& -c\left(y-\left(b-v^{2}\right) p(y)-c v^{2}\right) \\
& -D-\frac{\nu^{2}(p(y)-c)^{2}}{2} \\
& \left.-(1-\alpha) \frac{1-F(y)}{f(y)}(p(y)-c) \mathrm{d} s\right\} f(y) \mathrm{d} y \\
& \quad \frac{\mathrm{d} p(y)}{\mathrm{d} y}>0, \quad \forall y \in[y, \bar{y}] .
\end{aligned}
$$

Theorem 11. Under Case UP, the optimal contract $\left(p^{U P}(y), t^{U P}(y), e^{U P}(y)\right)$ satisfies

$$
\begin{gathered}
V^{\prime}\left(y-\left(b-v^{2}\right) p^{U P}(y)-c v^{2}\right) \\
=c-\left(\frac{1-\alpha}{b-v^{2}}\right)\left(\frac{1-F(y)}{f(y)}\right), \\
e^{U P}(y)=v\left(p^{U P}(y)-c\right), \\
t^{U P}(y)=D+\frac{v^{2}\left(p^{U P}(y)-c\right)^{2}}{2} \\
-\left(p^{U P}(y)-c\right)\left[y-\left(b-v^{2}\right) p^{U P}(y)-c v^{2}\right] \\
+\int_{\underline{y}}^{y}\left(p^{U P}(s)-c\right) \mathrm{d} s .
\end{gathered}
$$

Equation (24) indicates that, in the case of UP, the distortion of pricing depends on both the effort level and information rents, given by $\left((1-\alpha) /\left(b-v^{2}\right)\right)((1-F(y)) / f(y))$. Furthermore, note that the consumer's marginal utility is less 
than the marginal cost of the firm when $b>v^{2}$ and greater than the marginal cost of the firm in the case of $b<v^{2}$ except $y=\bar{y}$. Particularly, the consumer's marginal utility equals the marginal cost of the firm when $y=\bar{y}$. Moreover, as we have shown in Case OP, the consumer's marginal utility $V^{\prime}\left(y-b p^{\mathrm{OP}}(y)\right)$ is equal to the marginal cost of the firm when $y=\bar{y}$. Therefore, we can obtain

$$
V^{\prime}\left(\bar{y}-\left(b-v^{2}\right) p^{\mathrm{UP}}(\bar{y})-c v^{2}\right)=V^{\prime}(\bar{y})-b p^{\mathrm{OP}}(\bar{y})=c .
$$

From the above expression, together with (9), it is obvious that $q^{\mathrm{UP}}(\bar{y})=q^{\mathrm{OP}}(\bar{y})=q^{\mathrm{OF}}(y)$, yielding $p^{\mathrm{UP}}(\bar{y})>p^{\mathrm{OP}}(\bar{y})>$ $p^{\mathrm{OF}}(y)$. The first inequality means that although the demands under two cases are consistent; that is, the optimal demand has no distortion in the case of exerting effort, whereas the optimal price is distorted upwards so that the demand's decrease in the price equals the demand's increase in the effort level when $y=\hat{y}$, this is a remarkable conclusion compared with the classical adverse selection problem. The second inequality suggests that the presence of private information leads to the price's distortion.

In addition, similar to Case UF, the optimal effort level satisfies that the marginal profit of effort equals its marginal cost. However, the transfer payment $t^{\mathrm{UP}}(y)$ in (26) changes slightly. Intuitively, in order to achieve more demand, the firm exerts effort which results in extra cost. Therefore, in the case of private information, the consumer must pay both all the cost subsidy $D+\left(v^{2}\left(p^{\mathrm{UP}}(y)-c\right)^{2} / 2\right)-\left(p^{\mathrm{UP}}(y)-c\right)[y-(b-$ $\left.\left.v^{2}\right) p^{\mathrm{UP}}(y)-c \nu^{2}\right]$ to ensure the firm's participation and the information rents $\int_{y}^{y}\left(p^{\mathrm{UP}}(s)-c\right) \mathrm{d} s$ to guarantee the firm's truthful telling. In particular, there is no information rents when $y=\bar{y}$.

\subsection{The Effects of Information Structure}

Proposition 12. Let $p^{\mathrm{OF}}$ and $p^{\mathrm{OP}}$ be the optimal prices under Cases $O F$ and $O P$, respectively. Then

$$
p^{\mathrm{OF}} \geq p^{\mathrm{OP}} .
$$

To explain Proposition 12, notice firstly that, under Cases OF and OP, the optimal effort levels are zero; that is to say, the regulator prefers to set no effort to increase the demand. Therefore, there is no impact of effort level on the demand. Furthermore, without the firm's effort's effect on the demand, the reason that the optimal price $p^{\mathrm{OP}}$ is distorted downwards from that under Case OF is only determined by the presence of private information, which may give rise to information rents. And as a result, in order to limit information rents, the regulator has to lower the price from that under full information.

\subsection{The Effects of Effort}

Proposition 13. Let $p^{O P}$ and $p^{U P}$ be the optimal prices under Cases $O P$ and $U P$, respectively. When $b<v^{2}$,

$$
p^{O P}<p^{U P} \text {. }
$$

Proposition 13 suggests that the optimal price with the firms' effort is distorted upwards from that in the case of without the firm's effort, such a price distortion results from the effort level's effect. Particularly, when $b<v^{2}$, that is, the firm's effort level can bring about stronger effect on the demand although there exists moral hazard, surprisingly, the consumer's marginal utility still rises, that is,

$$
V^{\prime}\left(y-\left(b-v^{2}\right) p^{\mathrm{UP}}(y)-c v^{2}\right)>V^{\prime}\left(y-b p^{\mathrm{OP}}(y)\right) .
$$

From the above inequality, we will analyze how is the demand affected when the effort's effect and the price's effect coexist as follows. It is obvious that $y-\left(b-v^{2}\right) p^{\mathrm{UP}}-c v^{2} \leq y-b p^{\mathrm{OP}}$; that is to say, the demand under Case UP is not greater than that under Case OP; that is, $q^{\mathrm{UF}} \leq q^{\mathrm{OF}}$. This means that although the firm prefers to increase demand by exerting effort, the regulator still makes the demand reduced through improving the price considering the tradeoff between consumer utility and its cost. And when $b>v^{2}$, it is a pity, and there is no obvious relationship between $p^{\mathrm{UP}}$ and $p^{\mathrm{OP}}$, but we can deduce the relationship between $q^{\mathrm{UP}}$ and $q^{\mathrm{OP}}$. Since $V^{\prime}(y-$ $\left.\left(b-v^{2}\right) p^{\mathrm{UP}}-c v^{2}\right)<V^{\prime}\left(y-b p^{\mathrm{OP}}\right)$, it results in the following: $q^{\mathrm{UP}} \geq q^{\mathrm{OP}}$. Consequently, when moral hazard and adverse selection coexist, it is necessary to consider the difference between the effort's impact on the demand and the price's impact on the demand, which generates remarkable effects for the distortion of the consumer's marginal utility and the demand. In other words, the regulator will design different regulatory polices based on the difference.

\section{Conclusions}

This paper investigates a problem of how to regulate a firm who has private information about the market capacity, leading to adverse selection, and who can increase the market demand by exerting costly effort, resulting in moral hazard, in which the regulator as a regulatory policy designer offers a regulatory policy to the firm with the objective of maximizing a weighted sum of the consumer surplus and the firm's profit (i.e., the social total surplus). The regulatory policy menu consists of a unit price of products and a transfer payment. The regulator does not know the true market capacity, but he has a subjective assessment about it. Meanwhile, the regulator often cannot observe the firm's effort level. Therefore, under this setting, the problem facing the regulator is how does he design the optimal regulatory policy with the objective of maximizing the social total surplus, that is, a weighted sum of the consumer surplus and the firm's profit. And then we first analyze such problem that the firm's effort is observable and unobservable when the market capacity is known to the regulator, respectively. Then we extend the analysis to the scenario that the market capacity is private information.

We establish the following main findings. Firstly we show that the regulator will set the firms' effort level as zero under observable effort regardless of the market capacity being full or private information, that is, the effort has no impact on the optimal regulatory policy regardless of the market capacity being full or private information. It is worth noting that 
private information has no distortion for the effort level's decision by the regulator. Moreover, we also highlight that, it is necessary for regulator to consider the difference between the effort's impact on the demand and the price's impact on the demand, which may generate different distortion effects about the regulatory policy regardless of the market capacity being full or private information. In other words, based on the difference, the regulator will design different regulatory policies.

The possible extensions of this paper are as follows. On the one hand, considering how the regulator designs the optimal regulatory policy when facing an unregulated firm rival? On the other hand, we can investigate the optimal regulatory policy problem consisting of two competing regulated firms under adverse selection and moral hazard.

\section{Appendix}

Proof of Theorem 5. First note that at optimality the constraint in Model (8) must be binding. Otherwise, one can decrease $t$ and increase the objective function while keeping (8) satisfied. It follows from $\pi(p, t, e)=0$ that

$$
t=D+\psi(e)-(p-c)(y-b p+v e)
$$

Then, substituting $t$ into the regulator's objective function yields

$$
W(p, t, e)=V(y-b p+v e)-c(y-b p+v e)-D-\psi(e) .
$$

Note that $W(p, t, e)$ is separated with respect to $p$ and $e$; therefore, we can judge the concavity of the objective function with respect to $p$ and $e$, separately. By $b^{2} V^{\prime \prime} \leq 0$, we can obtain that the objective function is concave with respect to $p$. From the first-best condition, the optimal price $p^{\mathrm{OF}}$ satisfies $V^{\prime}\left(y-b p^{\mathrm{OF}}+v e\right)=c$. Similarly, it follows from $v^{2} V^{\prime \prime}-\psi^{\prime \prime}(e)<$ 0 that the objective function is concave with respect to $e$. Then the optimal price $e^{\mathrm{OF}}$ satisfies $V^{\prime}\left(y-b p+v e^{\mathrm{OF}}\right)=c+\psi^{\prime}\left(e^{\mathrm{OF}}\right)$. At last, by $p^{\mathrm{OF}}$ and $e^{\mathrm{OF}}$, the optimal transfer payment $t^{\mathrm{OF}}=$ $D+\psi\left(e^{\mathrm{OF}}\right)-\left(p^{\mathrm{OF}}-c\right)\left(y-b p^{\mathrm{OF}}+v e^{\mathrm{OF}}\right)$. The proof of Theorem 5 is complete.

Proof of Theorem 6. First, we consider the incentive constraint. Note that the firm's profit function is concave with respect to $e$; thus maximizing the profit, the firm solves the first-order condition $p-c-\psi^{\prime}(e)=0$ yielding the optimal effort $e^{\mathrm{UF}}=v(p-c)$ from $\psi(e)=e^{2} / 2$. With the optimal effort, the firm's profit becomes

$$
\begin{aligned}
\pi\left(p, t, e^{\mathrm{UF}}\right)= & (p-c)\left[y-\left(b-v^{2}\right) p-c v^{2}\right] \\
& -D-\frac{v^{2}(p-c)^{2}}{2}+t
\end{aligned}
$$

Now consider the participation constraint. Note that the participation constraint becomes $\pi\left(p, t, e^{\mathrm{UF}}\right) \geq 0$. Furthermore, the participation constraint must be binding; otherwise, the regulator can decrease $t$ until the firm only obtains her reservation profit. By $\pi\left(p, t, e^{\mathrm{UF}}\right)=0$, we have

$$
t=D+\frac{v^{2}(p-c)^{2}}{2}-(p-c)\left[y-\left(b-v^{2}\right) p-c v^{2}\right]
$$

Substituting $t$ and $e^{\mathrm{UF}}$ into the regulator's objective function yields

$$
\begin{aligned}
W\left(p, t, e^{\mathrm{UF}}\right)= & V\left(y-\left(b-v^{2}\right) p-c v^{2}\right) \\
& -c\left[y-\left(b-v^{2}\right) p-c v^{2}\right]-\frac{v^{2}(p-c)^{2}}{2} .
\end{aligned}
$$

It follows from $\left(-b+v^{2}\right)^{2} V^{\prime \prime}\left(y-\left(b-v^{2}\right) p-c v^{2}\right)-v^{2}<0$ that $W\left(p, t, e^{\mathrm{UF}}\right)$ is concave with respect to $p$. Then the optimal price $p^{\mathrm{UF}}$ satisfies

$$
V^{\prime}\left(y-\left(b-v^{2}\right) p^{\mathrm{UF}}-c v^{2}\right)=c-\frac{v^{2}}{b-v^{2}}\left(p^{\mathrm{UF}}-c\right) \text {. }
$$

Substituting $p^{\mathrm{UF}}$ and $e^{\mathrm{UF}}$ into $t$ yields $t^{\mathrm{UF}}=D+\left(\left(\nu^{2}\left(p^{\mathrm{UF}}-\right.\right.\right.$ $\left.\left.c)^{2}\right) / 2\right)-\left(p^{\mathrm{UF}}-c\right)\left[y-\left(b-v^{2}\right) p^{\mathrm{UF}}-c v^{2}\right]$. The proof of Theorem 6 is complete.

Proof of Proposition 7. It follows from $b<v^{2}$, together with $p \geq c$, that $V^{\prime}\left(y-\left(b-v^{2}\right) p^{\mathrm{UF}}-c v^{2}\right)>V^{\prime}\left(y-b p^{\mathrm{OF}}\right)$. Since $V^{\prime \prime}(\cdot) \leq 0$, then $y-\left(b-v^{2}\right) p^{\mathrm{UF}}-c \nu^{2} \leq y-b p^{\mathrm{OF}}$; that is, $b\left(p^{F}-p^{\mathrm{UF}}\right)+v^{2}\left(p^{\mathrm{UF}}-c\right) \leq 0$, because $p^{\mathrm{UF}} \geq c, p^{\mathrm{OF}} \leq$ $p^{\mathrm{UF}}$.

Proof of Proposition 8. The proof is similar to that of Proposition 10 where the firm's effort level is the regulator's decision variable.

Proof of Theorem 9. The proof is similar to that of Theorem 11 where the firm's effort level is the regulator's decision variable.

Assumption A.1. Consider $\mathrm{d} p(y) / \mathrm{d} y \leq \alpha / b$. This assumption gives the upper bound of the price's increasing with the market capacity.

Proof of Proposition 10. Similar to Model (12), we firstly solve the firm's optimal effort level. In particular, maximizing the firm's profit with respect to $e$, the firm solves the first-order condition yielding the optimal effort $e^{\mathrm{UP}}(y)=(\nu(p(y)-c) / a)$. Then substituting $e^{\mathrm{UP}}$ into the firm's profit yields

$$
\begin{aligned}
\pi( & \left.p(y), t(y), e^{\mathrm{UP}}(y), y\right) \\
= & (p(y)-c)\left[y-\left(b-v^{2}\right) p(y)-c v^{2}\right] \\
& -D-\frac{v^{2}(p(y)-c)^{2}}{2}+t(y) .
\end{aligned}
$$


Secondly, we consider the participation and the second constraints, and then we will obtain the equivalent model of Model (22). Particularly, the steps are as follows.

(1) First, we show that the second constraint of Model (22) can be written as

$$
\begin{aligned}
& {\left[y-\left(2 b-v^{2}\right) p(y)+c\left(b-v^{2}\right)\right]} \\
& \times \frac{\mathrm{d} p(y)}{\mathrm{d} y}+\frac{\mathrm{d} t(y)}{\mathrm{d} y}=0, \quad \forall y \in[\underline{y}, \bar{y}], \\
& \frac{\mathrm{d} p(y)}{\mathrm{d} y}>0, \quad \forall y \in[\underline{y}, \bar{y}] .
\end{aligned}
$$

Specifically, let $L(y, \hat{y})=(p(\hat{y})-c)\left[y-\left(b-v^{2}\right) p(\hat{y})-\right.$ $\left.c \nu^{2}\right]-D-\left(\nu^{2}(p(\hat{y})-c)^{2} / 2\right)+t(\hat{y})$, which denotes the profit of the firm when the market capacity about the product is $y$ but the firm misreports it as $\hat{y}$; that is, the firm chooses the regulatory policy $(p(\hat{y}), t(\hat{y}))$, where $y, \hat{y} \in[y, \bar{y}]$ and $y \neq \hat{y}$. Thus, for any given $y$, the second constraint of Model (22) can be written as

$$
L(y, y) \geq L(y, \hat{y}), \quad \forall \hat{y} \in[\underline{y}, \bar{y}] .
$$

That means that $L(y, \hat{y})$ obtains its maximal value at $(y, y)$; that is, the firm who knows the market capacity $y$ has no incentive to misreport the market capacity as $\hat{y}, \hat{y} \neq y$. Thus, $L(y, \widehat{y})$ satisfies the first-order condition $\left.(\partial L(y, \widehat{y}) / \partial \hat{y})\right|_{\hat{y}=y}=$ 0 and the second-order condition $\left.\left(\partial^{2} L(y, \widehat{y}) / \partial \hat{y}^{2}\right)\right|_{\hat{y}=y}<0$. It follows from the first-order condition that

$$
\begin{aligned}
& {\left[y-\left(2 b-\frac{v^{2}}{a}\right) p(y)+c\left(b-\frac{v^{2}}{a}\right)\right]} \\
& \quad \times \frac{\mathrm{d} p(y)}{\mathrm{d} y}+\frac{\mathrm{d} t(y)}{\mathrm{d} y}=0, \quad \forall y \in[\underline{y}, \bar{y}] .
\end{aligned}
$$

Differentiating both sides of (A.11) with respect to $y$ yields

$$
\begin{aligned}
& {\left[1-\left(2 b-v^{2}\right) \frac{\mathrm{d} p(y)}{\mathrm{d} y}\right] \frac{\mathrm{d} p(y)}{\mathrm{d} y}+\frac{\mathrm{d}^{2} t(y)}{\mathrm{d} y^{2}}} \\
& \quad+\left[y-\left(2 b-v^{2}\right) p(y)+c\left(b-v^{2}\right)\right] \frac{\mathrm{d}^{2} p(y)}{\mathrm{d} y^{2}}=0 .
\end{aligned}
$$

By the second-order condition, we can obtain

$$
\begin{aligned}
& -\left(2 b-v^{2}\right)\left(\frac{\mathrm{d} p(y)}{\mathrm{d} y}\right)^{2}+\frac{\mathrm{d}^{2} t(y)}{\mathrm{d} y^{2}} \\
& \quad+\left[y-\left(2 b-v^{2}\right) p(y)+c\left(b-v^{2}\right)\right] \frac{\mathrm{d}^{2} p(y)}{\mathrm{d} y^{2}}=0<0 .
\end{aligned}
$$

Applying (A.12) to Inequality (A.13) yields

$$
\frac{\mathrm{d} p(y)}{\mathrm{d} y}>0, \quad \forall y \in[\underline{y}, \bar{y}] .
$$

That is, the second constraint of Models $(22) \Rightarrow($ A.8) and (A.9).

On the other hand, by $\mathrm{d} p(y) / \mathrm{d} y>0$ integrating (A.8) yields

$$
\begin{aligned}
t(y) & t(\hat{y}) \\
= & \int_{\hat{y}}^{y}\left[\left(2 b-v^{2}\right) p(s)-s-c\left(b-v^{2}\right)\right] \frac{\mathrm{d} p(s)}{\mathrm{d} s} \mathrm{~d} s \\
\geq & \int_{\hat{y}}^{y}\left[\left(2 b-v^{2}\right) p(s)-y-c\left(b-v^{2}\right)\right] \frac{\mathrm{d} p(s)}{\mathrm{d} s} \mathrm{~d} s \\
= & \left(b-\frac{v^{2}}{2}\right) p(y)^{2}-\left(b-\frac{v^{2}}{2}\right) p(\hat{y})^{2}-p(y) y+p(\hat{y}) y \\
& -c\left(b-v^{2}\right) p(y)+c\left(b-v^{2}\right) p(\hat{y})+c y \\
& -c y+\frac{c^{2} v^{2}}{2}-\frac{c^{2} v^{2}}{2}+D-D \\
= & (p(\hat{y})-c)\left[y-\left(b-v^{2}\right) p(\hat{y})-c v^{2}\right] \\
& -D-\frac{v^{2}(p(\hat{y})-c)^{2}}{2}+D+\frac{v^{2}(p(y)-c)^{2}}{2} \\
& -(p(y)-c)\left[y-\left(b-v^{2}\right) p(y)-c v^{2}\right],
\end{aligned}
$$

when $y>\hat{y}$, and

$$
\begin{aligned}
& t(y)-t(\hat{y}) \\
&=\int_{\hat{y}}^{y}\left[\left(2 b-v^{2}\right) p(s)-s-c\left(b-v^{2}\right)\right] \frac{\mathrm{d} p(s)}{\mathrm{d} s} \mathrm{~d} s \\
&=-\int_{y}^{\hat{y}}\left[\left(2 b-v^{2}\right) p(s)-s-c\left(b-v^{2}\right)\right] \frac{\mathrm{d} p(s)}{\mathrm{d} s} \mathrm{~d} s \\
& \geq-\int_{y}^{\hat{y}}\left[\left(2 b-v^{2}\right) p(s)-y-c\left(b-v^{2}\right)\right] \frac{\mathrm{d} p(s)}{\mathrm{d} s} \mathrm{~d} s \\
&=(p(\hat{y})-c)\left[y-\left(b-v^{2}\right) p(\hat{y})-c v^{2}\right] \\
&-D-\frac{\nu^{2}(p(\hat{y})-c)^{2}}{2}+D+\frac{\nu^{2}(p(y)-c)^{2}}{2} \\
&-(p(y)-c)\left[y-\left(b-v^{2}\right) p(y)-c v^{2}\right],
\end{aligned}
$$

when $y<\hat{y}$. Therefore, the second constraint of Model (22) is satisfied. That is, (A.8) and (A.9) $\Rightarrow$ the second constraint of Model (22).

(2) Second, the participation constraint of Model (22) can be written as

$$
\begin{aligned}
t(\underline{y})= & +\frac{v^{2}(p(\underline{y})-c)^{2}}{2} \\
& -(p(\underline{y})-c)\left[\underline{y}-\left(b-v^{2}\right) p(\underline{y})-c \nu^{2}\right] .
\end{aligned}
$$


In particular, note the profit of the firm:

$$
\begin{aligned}
\pi( & \left.p(y), t(y), e^{\mathrm{UP}}(y), y\right) \\
= & (p(y)-c)\left[y-\left(b-v^{2}\right) p(y)-c \nu^{2}\right] \\
& -D-\frac{\nu^{2}(p(y)-c)^{2}}{2}+t(y),
\end{aligned}
$$

therefore,

$$
\begin{aligned}
& \frac{\mathrm{d} \Pi\left(p(y), t(y), e^{\mathrm{UP}}(y), y\right)}{\mathrm{d} y} \\
& =\left[y-\left(2 b-v^{2}\right) p(y)+c\left(b-v^{2}\right)\right] \frac{\mathrm{d} p(y)}{\mathrm{d} y} \\
& \quad+p(y)-c+\frac{\mathrm{d} t(y)}{\mathrm{d} y} .
\end{aligned}
$$

It follows from (A.8) and $p \geq c$ that

$$
\frac{\mathrm{d} \Pi\left(p(y), t(y), e^{\mathrm{UP}}(y), y\right)}{\mathrm{d} y}=p(y)-c \geq 0,
$$

which means that $\Pi\left(p(y), t(y), e^{\mathrm{UP}}(y), y\right)$ is increasing with respect to $y$. Consequently, the participation constraint of Model (22) is equivalent to

$$
\begin{aligned}
\Pi\left(p(\underline{y}), t(\underline{y}), e^{\mathrm{UP}}, \underline{y}\right) \\
=(p(\underline{y})-c)\left[\underline{y}-\left(b-v^{2}\right) p(\underline{y})-c v^{2}\right] \\
-D-\frac{v^{2}(p(\underline{y})-c)^{2}}{2}+t(\underline{y}) \geq 0 .
\end{aligned}
$$

In fact, the constraint (A.21) is binding under the optimal regulatory policy. Since, for any feasible regulatory policy $\left(p(\cdot), t(\cdot), e^{\mathrm{UF}}(\cdot)\right)$ of Model (22), a new regulatory policy $\left(p(\cdot), t^{*}(\cdot), e^{\mathrm{UF}}(\cdot)\right)$ can be established, where $t^{*}(y)=D+$ $\left(\nu^{2}(p(\underline{y})-c)^{2} / 2\right)-(p(\underline{y})-c)\left[\underline{y}-\left(b-v^{2}\right) p(\underline{y})-c \nu^{2}\right]$ and

$$
\frac{\mathrm{d} t^{*}(y)}{\mathrm{d} y}=\frac{\mathrm{d} t(y)}{\mathrm{d} y} \text {. }
$$

It is easy to testify that $\left(p(\cdot), t^{*}(\cdot), e^{\mathrm{UF}}(\cdot)\right)$ is also feasible for Model (22) and $t^{*}(y) \leq t(y)$ for all $y \in[y, \bar{y}]$. Since $\mathrm{d} W / \mathrm{d} t=$ $\alpha-1 \leq 0$; that is, the social total surplus is nonincreasing with respect to $t$, hence,

$$
\begin{aligned}
& W\left(p(y), t^{*}(y), e^{\mathrm{UF}}(y), y\right) \\
& \quad \geq W\left(p(y), t(y), e^{\mathrm{UF}}(y), y\right),
\end{aligned}
$$

which means that the regulator will choose the least transfer payment satisfying the participation constraint. Thus, an optimal regulatory policy should satisfy

$$
\begin{aligned}
t(\underline{y})=D & +\frac{v^{2}(p(\underline{y})-c)^{2}}{2} \\
& -(p(\underline{y})-c)\left[\underline{y}-\left(b-v^{2}\right) p(\underline{y})-c v^{2}\right] .
\end{aligned}
$$

(3) Third, we can verify that the objective function of Model (22) can be written as

$$
\begin{aligned}
\int_{\underline{y}}^{\bar{y}}\left\{V\left(y-\left(b-v^{2}\right) p(y)-c v^{2}\right)\right. \\
-c\left(y-\left(b-v^{2}\right) p(y)-c v^{2}\right)-D \\
\quad-\frac{\nu^{2}(p(y)-c)^{2}}{2} \\
\left.-(1-\alpha) \frac{1-F(y)}{f(y)}[p(y)-c] \mathrm{d} s\right\} f(y) \mathrm{d} y .
\end{aligned}
$$

Specifically, integrating (A.8) yields

$$
\begin{aligned}
t(y) & -t(\underline{y}) \\
= & \int_{\underline{y}}^{y}\left[\left(2 b-v^{2}\right) p(s)-s-c\left(b-v^{2}\right)\right] \frac{\mathrm{d} p(s)}{\mathrm{d} s} \mathrm{~d} s \\
= & (p(\underline{y})-c)\left[\underline{y}-\left(b-v^{2}\right) p(\underline{y})-c v^{2}\right] \\
& -D-\frac{v^{2}(p(\underline{y})-c)^{2}}{2}+D+\frac{\nu^{2}(p(y)-c)^{2}}{2} \\
& -(p(y)-c)\left[y-\left(b-v^{2}\right) p(y)-c v^{2}\right] \\
& +\int_{y}^{y}[p(s)-c] \mathrm{d} s .
\end{aligned}
$$

Therefore,

$$
\begin{aligned}
t(y)= & (p(\underline{y})-c)\left[\underline{y}-\left(b-v^{2}\right) p(\underline{y})-c v^{2}\right] \\
& -D-\frac{v^{2}(p(\underline{y})-c)^{2}}{2}+t(\underline{y})+D+\frac{v^{2}(p(y)-c)^{2}}{2} \\
& -(p(y)-c)\left[y-\left(b-v^{2}\right) p(y)-c v^{2}\right] \\
& +\int_{\underline{y}}^{y}(p(s)-c) \mathrm{d} s .
\end{aligned}
$$

By (A.17), the transfer payment:

$$
\begin{aligned}
t(y)= & D+\frac{v^{2}(p(y)-c)^{2}}{2} \\
& -(p(y)-c)\left[y-\left(b-v^{2}\right) p(y)-c v^{2}\right] \\
& +\int_{\underline{y}}^{y}(p(s)-c) \mathrm{d} s .
\end{aligned}
$$

Then the firm's profit:

$$
\Pi\left(p(y), t(y), e^{\mathrm{UP}}(y), y\right)=\int_{\underline{y}}^{y}(p(s)-c) \mathrm{d} s .
$$


Substituting $t(y)$ and $\Pi\left(p(y), t(y), e^{\mathrm{UP}}(y), y\right)$ into the objective function of the regulator yields

$$
\begin{aligned}
W\left(p(y), t(y), e^{\mathrm{UP}}(y), y\right) & = \\
= & -c\left(y-\left(b-v^{2}\right) p(y)-c v^{2}\right) \\
& \quad-\frac{v^{2}(p(y)-c)^{2}}{2} \\
& -D-(1-\alpha) \int_{\underline{y}}^{y}(p(s)-c) \mathrm{d} s .
\end{aligned}
$$

Thus

$$
\begin{aligned}
& \frac{\mathrm{d} W\left(p(y), t(y), e^{\mathrm{UP}}(y), y\right)}{\mathrm{d} y} \\
& =\left(V^{\prime}-c\right)\left[1-\left(b-v^{2}\right) \frac{\mathrm{d} p(y)}{\mathrm{d} y}\right] \\
& \quad-\left(1-\alpha+v^{2} \frac{\mathrm{d} p(y)}{\mathrm{d} y}\right)[p(y)-c] \\
& \geq\left(1-\alpha+v^{2} \frac{\mathrm{d} p(y)}{\mathrm{d} y}\right)\left(V^{\prime}-p(y)\right),
\end{aligned}
$$

where the inequality holds from Assumption $\mathrm{d} p(y) / \mathrm{d} y \leq$ $\alpha / b$. Furthermore, it follows from $V^{\prime} \geq p$ and $1-\alpha+$ $v^{2}(\mathrm{~d} p(y) / \mathrm{d} y) \geq 0$ that $\mathrm{d} W\left(p(y), t(y), e^{\mathrm{UP}}(y), y\right) / \mathrm{d} y \geq 0$; that is, the expected social total surplus is increasing with respect to $y$. It follows from Lemma 4 that

$$
\begin{aligned}
E\left[W\left(p(Y), t(Y), e^{\mathrm{UP}}(Y), Y\right)\right] \\
=\int_{\underline{y}}^{\bar{y}}\left\{V\left(y-\left(b-v^{2}\right) p(y)-c \nu^{2}\right)\right. \\
-c\left(y-\left(b-v^{2}\right) p(y)-c \nu^{2}\right) \\
-D-\frac{\nu^{2}(p(y)-c)^{2}}{2} \\
\left.-(1-\alpha) \int_{\underline{y}}^{y}[p(s)-c] \mathrm{d} s\right\} f(y) \mathrm{d} y .
\end{aligned}
$$

Integrating (A.32) by parts yields

$$
\begin{aligned}
\int_{\underline{y}}^{\bar{y}}\left\{V\left(y-\left(b-v^{2}\right) p(y)-c v^{2}\right)\right. \\
-c\left(y-\left(b-v^{2}\right) p(y)-c v^{2}\right)-D \\
\quad-\frac{v^{2}(p(y)-c)^{2}}{2} \\
\left.-(1-\alpha) \frac{1-F(y)}{f(y)}[p(s)-c] \mathrm{d} s\right\} f(y) \mathrm{d} y .
\end{aligned}
$$

According to (1), (2), and (3), we can obtain easily the results of Proposition 10.

Proof of Theorem 11. First, the concavity of the objective function in Model (23) is proved. Since the second variation

$$
\begin{aligned}
& \delta^{2} E {\left[W\left(p(Y), t(Y), e^{\mathrm{UP}}(Y), Y\right)\right] } \\
&=\int_{\underline{y}}^{\bar{y}}\left[V^{\prime \prime}\left(y-\left(b-v^{2}\right) p(y)-c v^{2}\right)\left(b-v^{2}\right)^{2}\right] f(y) \mathrm{d} y,
\end{aligned}
$$

according to $V^{\prime \prime}(\cdot) \leq 0$, we can obtain $\delta^{2} E[W(p(Y)$, $\left.\left.t(Y), e^{\mathrm{UP}}(Y), Y\right)\right] \leq 0$; that is, $E\left[W\left(p(Y), t(Y), e^{\mathrm{UP}}(Y), Y\right)\right]$ is concave with respect to $p$. In order to maximize the regulator's objective function, it follows from the first-order condition, that is, $\delta E\left[W\left(p(Y), t(Y), e^{\mathrm{UP}}(Y), Y\right)\right]=0$, that

$$
\begin{aligned}
& \int_{\underline{y}}^{\bar{y}}\left\{V^{\prime}\left(y-\left(b-v^{2}\right) p(y)-c v^{2}\right)\right. \\
& \left.\quad-c+\left(\frac{1-\alpha}{b-v^{2}}\right)\left(\frac{1-F(y)}{f(y)}\right)\right\}(\delta p) f(y) \mathrm{d} y=0 .
\end{aligned}
$$

Thus, $V^{\prime}\left(y-\left(b-v^{2}\right) p(y)-c v^{2}\right)-c+\left((1-\alpha) /\left(b-v^{2}\right)\right)((1-$ $F(y)) / f(y))=0$ holds.

On the other hand, (24) also means that the constraint $\mathrm{d} p(y) / \mathrm{d} y>0$ holds. Particularly, note that the derivation of (24) with respect to $y$ is

$$
\begin{aligned}
& V^{\prime \prime}\left(1-\left(b-\frac{v^{2}}{a}\right) \frac{\mathrm{d} p(y)}{\mathrm{d} y}\right) \\
& \quad+\left(\frac{1-\alpha}{b-\left(v^{2} / a\right)}\right) \frac{\mathrm{d}}{\mathrm{d} y}\left(\frac{1-F(y)}{f(y)}\right)=0 .
\end{aligned}
$$

It follows from $(\mathrm{d} / \mathrm{d} y)(f(y) /(1-F(y))) \geq 0$ that $(\mathrm{d} / \mathrm{d} y)((1-$ $F(y)) / f(y)) \leq 0$. Incorporating it into (A.36) yields $\mathrm{d} p(y) / \mathrm{d} y>0, \forall y \in[\underline{y}, \bar{y}]$. Therefore, the proof of $p(y)$ satisfying (24) is complete.

It follows from (A.28) that (26) holds. The proof of Theorem 11 is complete.

Proof of Proposition 12. It follows from (9) and (19) that $V^{\prime}\left(y-\left(b-v^{2}\right) p^{\mathrm{UF}}-c v^{2}\right)>V^{\prime}\left(y-b p^{\mathrm{OF}}\right)$; together with $V^{\prime \prime}(\cdot) \leq 0$, we can obtain the result of Proposition 12 .

Proof of Proposition 13. Using the same method, by (19) and (24), we can easily obtain the result of Proposition 13.

\section{Conflict of Interests}

The authors declare that there is no conflict of interests regarding the publication of this paper. 


\section{Acknowledgments}

This work was supported by the National Natural Science Foundation of China under Grants no. 71271151 and no. 71301114 and the research fund from the Specialized Research Fund for the Doctoral Program of Higher Education under Grant no. 20130032110015.

\section{References}

[1] J. Laffont and D. Martimort, The Theory of Incentives: The Principal-Agent Model, Princeton University Press, Princeton, NJ, USA, 2002.

[2] P. Bolton and M. Dewatripont, Contract Theory, MIT Press, Cambridge, Mass, USA, 2005.

[3] D. P. Baron and R. B. Myerson, "Regulating a monopolist with unknown costs," Econometrica, vol. 50, no. 4, pp. 911-930, 1982.

[4] T. Lewis and D. Sappington, "Regulating a monopolist with unknown demand," The American Economic Review, vol. 78, no. 5, pp. 986-998, 1988.

[5] D. Baron and D. Besanko, "Regulating asymmetric information, and auditing," The RAND Journal of Economics, vol. 15, no. 4, pp. 447-470, 1984.

[6] D. Sappington, "Optimal regulation of a multiproduct monopoly with uknown technological capabilities," The Bell Journal of Economics, vol. 14, no. 2, pp. 453-463, 1983.

[7] D. Sappington and D. Sibley, "Regulating without cost information: the incremental surplus subsidy scheme," International Economic Review, vol. 29, no. 2, pp. 297-306, 1988.

[8] J.-J. Laffont and J.-C. Rochet, "Regulation of a risk averse firm," Games and Economic Behavior, vol. 25, no. 2, pp. 149-173, 1998.

[9] J. Laffont and J. Tirole, A Theory of Incentives in Procurement and Regulation, MIT Press, Cambridge, Mass, USA, 1993.

[10] I. Aguirre and A. Beitia, "Regulating a monopolist with unknown demand: costly public funds and the value of private information," Journal of Public Economic Theory, vol. 6, no. 5, pp. 693-706, 2004.

[11] Y. Lan, R. Zhao, and W. Tang, "A yardstick competition approach to a multi-firm regulation problem under asymmetric information," Journal of Computational and Applied Mathematics, vol. 249, pp. 24-36, 2013.

[12] T. Lewis and D. Sappington, "Regulating a monopolist with unknown demand and cost functions," The RAND Journal of Economics, vol. 19, no. 3, pp. 438-457, 1988.

[13] S. Cowan, "Optimal risk allocation for regulated monopolies and consumers," Journal of Public Economics, vol. 88, no. 1-2, pp. 285-303, 2004.

[14] T. Lewis and D. Sappington, "Incentives for conservation and quality improvement by public utilities," The American Economic Review, vol. 82, no. 5, pp. 1321-1340, 1992.

[15] T. Lewis and D. Sappington, "Incentives for monitoring quality," The RAND Journal of Economics, vol. 22, no. 3, pp. 370-384, 1991.

[16] D. M. Dalen, "Regulation of quality and the ratchet effect: does unverifiability hurt the regulator?" Journal of Regulatory Economics, vol. 11, no. 2, pp. 139-155, 1997.

[17] J. Laffont and J. Tirole, "Using cost observation to regulate firms," Journal of Political Economy, vol. 94, no. 3, pp. 614-641, 1986.
[18] I. Perrigne and Q. Vuong, "Nonparametric identification of a contract model with adverse selection and moral hazard," Econometrica, vol. 79, no. 5, pp. 1499-1539, 2011.

[19] B. Liu, Uncertainty Theory, vol. 154 of Studies in Fuzziness and Soft Computing, Springer, Berlin, Germany, 2nd edition, 2007.

[20] B. Liu, "Uncertain set theory and uncertain inference rule with application to uncertain control," Journal of Uncertain Systems, vol. 4, no. 2, pp. 83-98, 2010.

[21] Y. Zhu, "Uncertain optimal control with application to a portfolio selection model," Cybernetics and Systems, vol. 41, no. 7, pp. 535-547, 2010.

[22] X. Chen and B. Liu, "Existence and uniqueness theorem for uncertain differential equations," Fuzzy Optimization and Decision Making, vol. 9, no. 1, pp. 69-81, 2010.

[23] Y. Lan, R. Zhao, and W. Tang, "A bilevel fuzzy principalagent model for optimal nonlinear taxation problems," Fuzzy Optimization and Decision Making, vol. 10, no. 3, pp. 211-232, 2011.

[24] Y.-F. Lan, Y.-K. Liu, and G.-J. Sun, "Modeling fuzzy multiperiod production planning and sourcing problem with credibility service levels," Journal of Computational and Applied Mathematics, vol. 231, no. 1, pp. 208-221, 2009.

[25] Y. Lan, R. Zhao, and W. Tang, "A fuzzy supply chain contract problem with pricing and warranty," Journal of Intelligent and Fuzzy Systems, 2013.

[26] G. Wang, W. Tang, and R. Zhao, "An uncertain price discrimination model in labor market," Soft Computing, vol. 17, no. 4, pp. 579-585, 2013.

[27] R. Mu, Y. Lan, and W. Tang, "An uncertain contract model for rural migrant worker's employment problems," Fuzzy Optimization and Decision Making, vol. 12, no. 1, pp. 29-39, 2013.

[28] Y. Lan, R. Zhao, and W. Tang, "Minimum risk criterion for uncertain production planning problems," Computers \& Industrial Engineering, vol. 61, no. 3, pp. 591-599, 2011.

[29] X. Feng and G. Yuan, "Optimizing two-stage fuzzy multiproduct multi-period production planning problem," Information, vol. 14, no. 6, pp. 1879-1893, 2011.

[30] T. Huang, R. Zhao, and W. Tang, "Risk model with fuzzy random individual claim amount," European Journal of Operational Research, vol. 192, no. 3, pp. 879-890, 2009.

[31] R. B. Myerson, "Incentive compatibility and the bargaining problem," Econometrica, vol. 47, no. 1, pp. 61-73, 1979. 


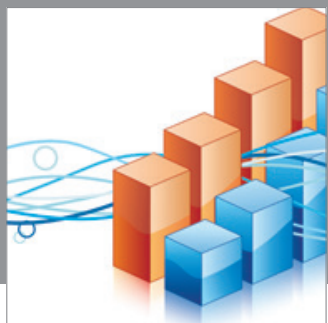

Advances in

Operations Research

mansans

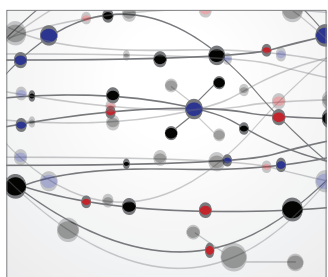

The Scientific World Journal
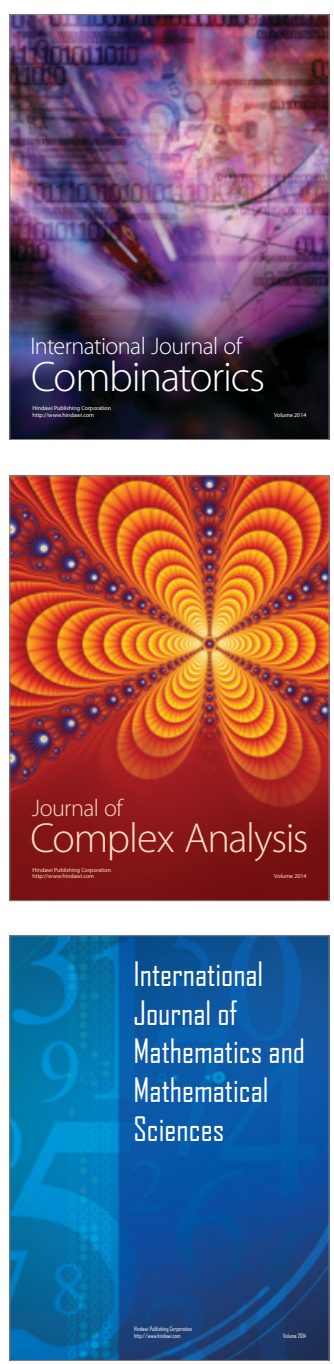
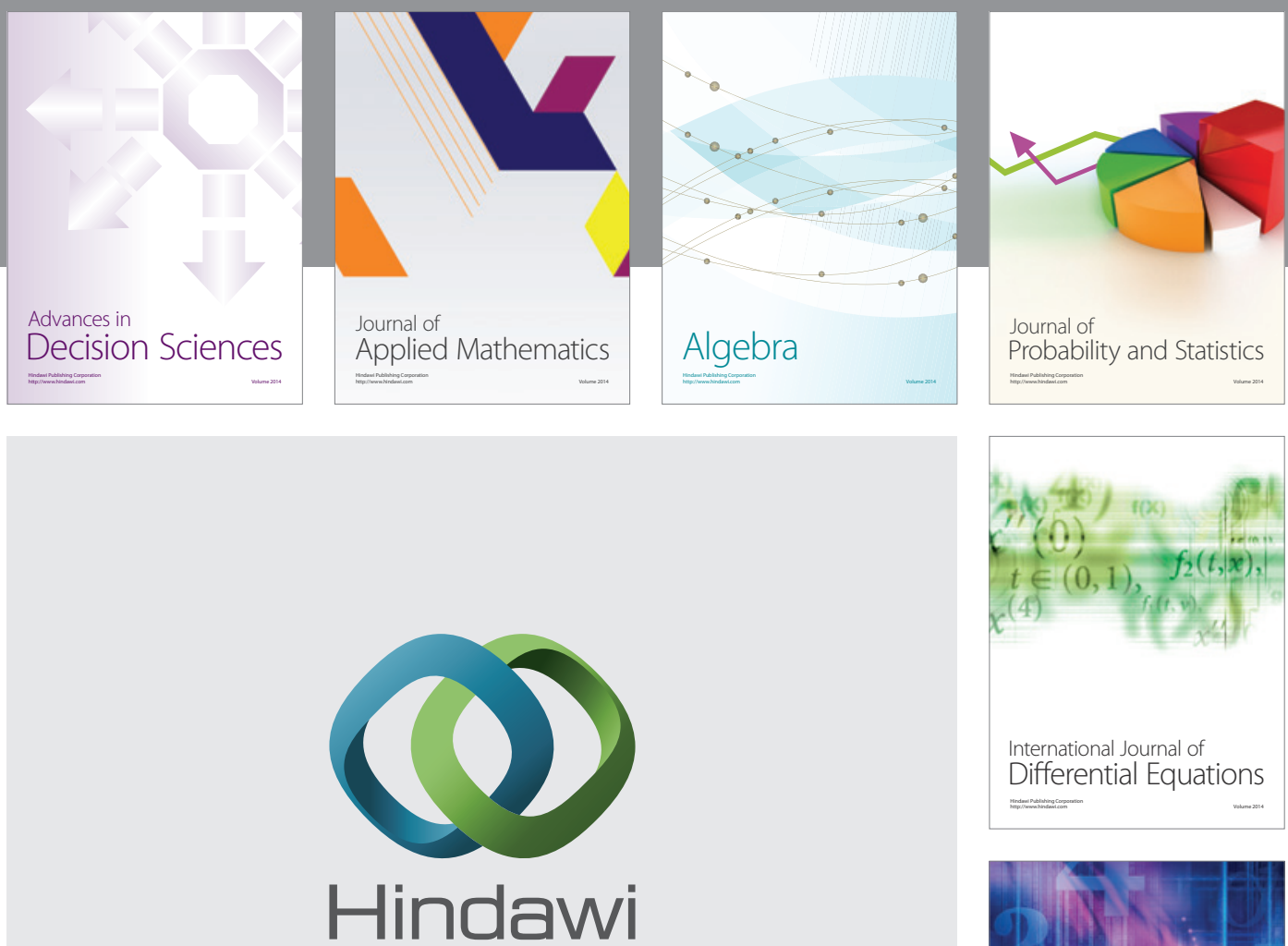

Submit your manuscripts at http://www.hindawi.com
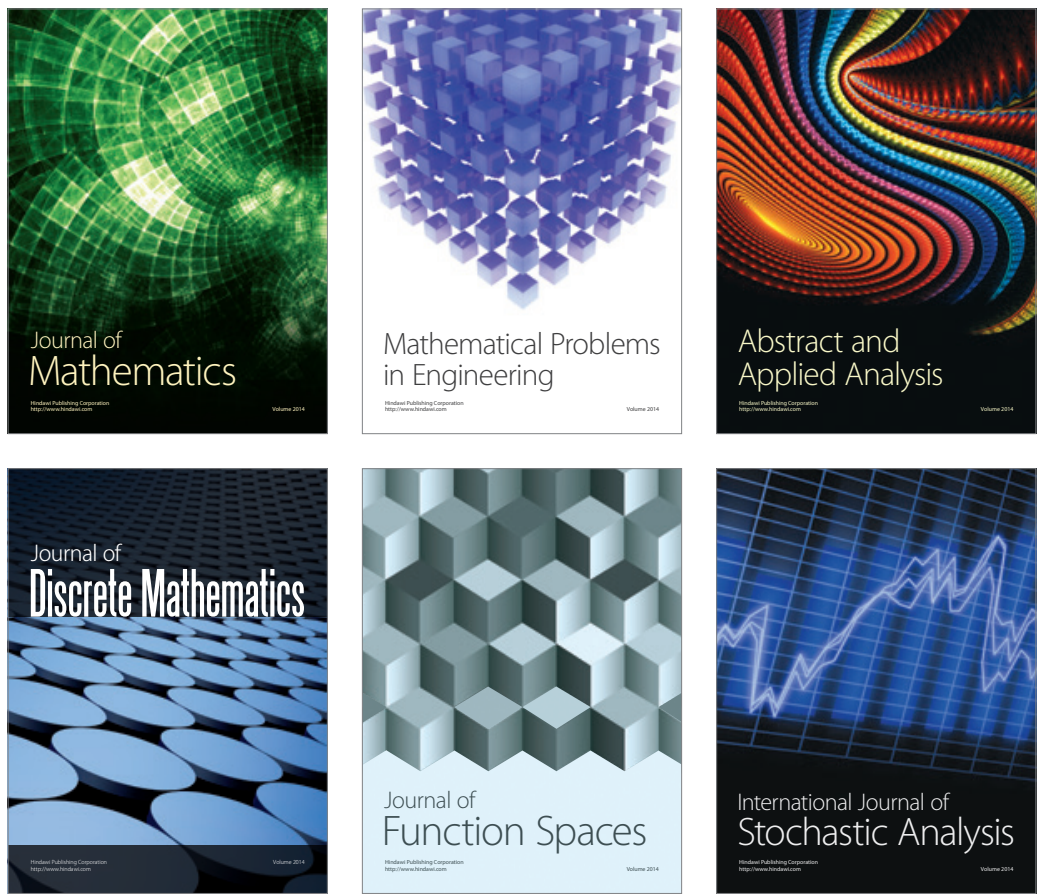

Journal of

Function Spaces

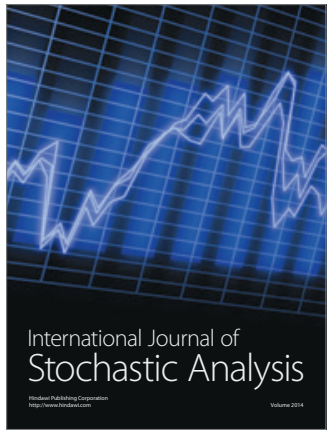

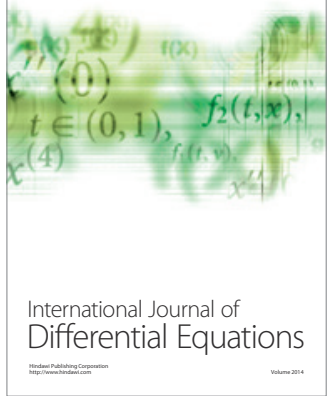
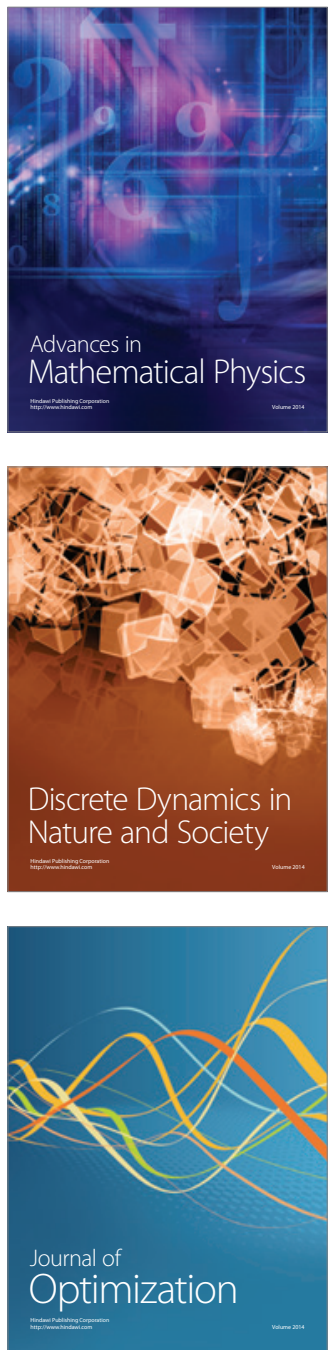